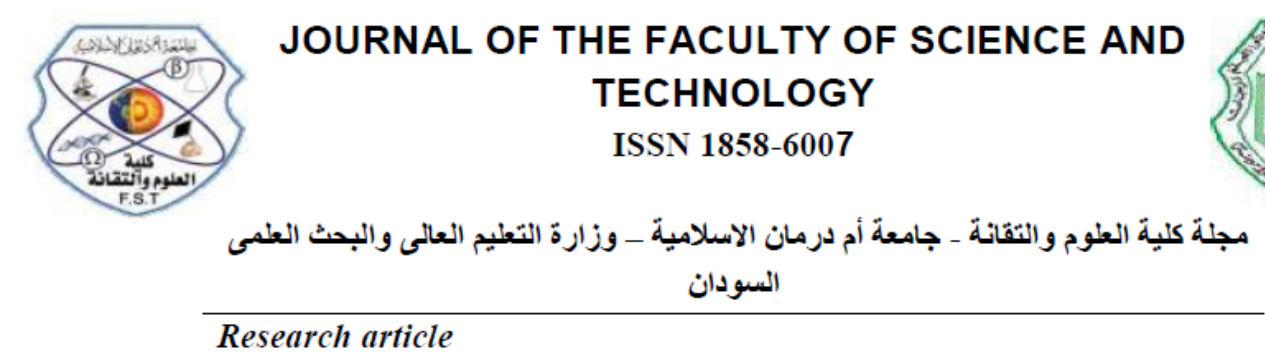

\title{
A comparative study of three conventional methods for diagnosis urinary schistosomiasis.
}

\author{
Abosalif, K. $\mathrm{O}^{1}$;Ahmed, A. $\mathrm{A}^{2}$; Shammat. I. $\mathrm{M}^{3}$;Aljafari. A. $\mathrm{S}^{4}$; Afifi, A.A ${ }^{* 5}$ and Clive, J. Shiff ${ }^{6}$ \\ ${ }^{1}$ Department of Medical Parasitology, Faculty of Medical Laboratory Sciences- Omdurman Islamic \\ University \\ ${ }^{2}$ Department of Zoology, Faculty of Science, University of Khartoum \\ ${ }^{3}$ Department of Molecular Biology, Faculty of Medical Laboratory Sciences- Omdurman Islamic \\ University \\ ${ }^{4}$ Department of Medical Parasitology, Faculty of Medical Laboratory Sciences- Alneelain University \\ ${ }^{5}$ Department of Zoology, Faculty of Sciences and Technology - Omdurman Islamic University \\ (corresponding Author) \\ ${ }^{6}$ Department of Molecular Microbiology and Immunology, Bloomberg School of Public Health, \\ Johns Hopkins university
}

\section{Abstract}

The general objective of this comparative study was the evaluation of threediagnostictechniques(sedimentation technique using centrifugation, filtration techniques using millipore filter and Ninhydrine stained filter paper) conventional approaches. This was carried out at Alzaidab, River Nile State, Northern Sudan on 93 school children. The study involved the collection of samples from school children of 7 years age and above. A questionnaire was distributed to collect data on gender, age and water contact activities. The examinations on all samples were carried out applying the methods previously mentioned. The results revealed that the overall prevalence rates of Schistosomahaematobium in Alzaidab Nile State were $16.1 \%, 24.7 \%$ and $24.7 \%$ using the centrifugation, syringe filtration millipore, ninhydrin - filter paper staining method respectively. According to gender, males showed higher prevalence rates than females using all the techniques mentioned and the highest prevalence rate in males $(36.1 \%)$ was reported bythesyringe filtration millipore and ninhydrin - filter paper staining method. According to age groups, the highest prevalence rate was reported among the group of children over 13 years of age, using all the techniques. The high prevalence rate $(64.3 \%)$ among the above mentioned group (over 13 year's of age) was shown by the syringe filtration millipore and ninhydrin - filter paper staining method. The highest prevalence rate 
amongthose who had water contact (32.9\%) was shown by the syringe filtration millipore and ninhydrin - filter paper staining method.It was found that the syringe filtration millipore and ninhydrin - filter paper staining methods gave identical and reproducible results, yet the ninhydrin - filter paper staining does not fit for field practice since it can only be carried out in the

laboratory.

\section{Introduction}

Bilharzia (schistosomiasis) occurs in the tropics and subtropics and is one of the most important parasitic diseases of humans. Human disease is caused by Schistosomahaematobium,

Schistosomamansoni, Schistosomajaponicum, less frequently, Schistosomamekongi and Schistosomaintercalatum $\left.{ }^{(\mathbf{1},}{ }^{2}\right)$.These flukes reside in the blood vessels of the gut or the bladder, causing fever, pain and bleeding. Bladder cancer or oesophagealvarices may follow. Diagnosis is difficult, requiring detection of parasite eggs in stool, urine or gut/bladder biopsies.

Infection with cercariae occurs through intact skin via contact with infested water. The penetration of the cercariae is followed by Katayama syndrome; an acute syndrome with fever, rash and eosinophilia. The syndrome is thought to be caused by antigen excess due to the presence of schistosomulae in the blood and the beginning of egg deposition(Gryseelset al., 2006 and Ross et al., 2007).After maturation, the adult male and female worms mate and actively migrate to their target organs(Gryseelset al., 2006 and Ross et al., 2007).Schistosomahaematobium resides in the wall of the bladder, sacral and pelvic blood vessels surrounding the urinary tract. The other mentioned species reside in mesenteric veins. After deposition of eggs in the capillary system, eggs penetrate the mucosa of target organs and are excreted in urine or faeces.

Sequelae of acute and chronic infection include hepato-splenic diseases, portal hypertension with varices, pulmonary hypertension, squamous cell cancer of the bladder, liver fibrosis, and less common conditions such as myelo-radiculitis and female genital schistosomiasis. Co-infections with Hepatitis C virus (HCV) and Schistosoma may also modify the course of hepatitis C (Ross et al., 2002 and Quack et al., 2006).Historically speaking, the ancient kingdoms of the Nile basin have always been in close touch with the disease. This happened through trade, invasion, immigration due to political oppression, or natural disasters such as floods, drought and famines(Hammamet al., 1933).The disease was well known and documented amongst the ancient Egyptians. It is still endemic amongst the rural population. The history of schistosomiasis in other parts of the Nile 
valley is not as yet clear. However, it is known to occur along the shores of Lake Victoria, Lake Tana and also all along the course of the Nile down to the Egyptian delta. It is well known that the Egyptians have invaded and dominated the Nile valley during ancient times and also during the 19th century as a part of the Ottoman Empire(Eltayeb, 1998). The variation in transmission patterns in different endemic areas of urinary schistosomiasismakes it almost impossible to set up a "standard" control strategy. In fact, real and meaningful control requires recognition of the importance of this disease. Perhaps the impact of this disease on the financial and socioeconomical level as well as the productivity of handicapped individuals in the affected community, not to speak of the numerous fatalities, can be an indicator of facing an important foe who can never be overlooked. Moreover the recent researches show that the complication of an acute and chronic infection of urinary schistosomiasis includes hepato-splenic disease, portal hypertension with varices, pulmonary hypertension, squamous cell cancer of the bladder and liver fibrosis. Indeed, the recognition of the importance of appropriate investigation and diagnostic methods become evident and essential for the identification of the parasite and lead to determining the precise treatment. All that necessitates the selection of the most accurate investigation techniques, which can yield reproducible and reliable results. This is an attempt to investigate the readability, sensitivity and specificity of three conventional methods (sedimentation technique using centrifugation, filtration techniques using millipore filter and Ninhydrine stained filter paper) in detecting urinary schistosomiasis.

\section{Materials and methods:}

Study design:This is a cross-sectional and descriptive community-based study of qualitative and quantitative approach.

Study area: The study was conducted in Alzaidab, River Nile state, Northern Sudan. Alzaidab area is located between longitudes $17^{\circ} 20^{`} \mathrm{~N}-17^{\circ} 39^{`} \mathrm{~N}$ and $33^{\circ} 46$ ${ }^{\prime} \mathrm{E}-33^{\circ} 57^{`} \mathrm{E}$ in the River Nile state on the west bank of the River Nile.

\section{Sample size and study population:}

In this study, 93 individuals were enrolled. Participants of both genders living at the study area territories selected were of the age between 5 and 18 years old (school age children). Cohort children participants were selected according to the WHO criteria. These criteria required the categorization of the school children into three groups; from 1 st to 3 rd, 4 th to 6 th, and from 7 th to the 8 th grade. From each group 50 pupils were selected.

Sampling technique was randomized and non-probability hypothesis was considered. 


\section{Samples collection:}

From each participant $60 \mathrm{ml}$ of fresh voided urine was collected. $10 \mathrm{ml}$ sample of this specimen was transferred into a centrifuge tube and subjected to centrifugation. Another $10 \mathrm{ml}$ sample was filtered through Millipore filter. The rest of the specimen was passed through Whatman paper No. 3 and another commercial filter paper for further Ninhydrin-filter paper staining.

\section{Methods:}

\section{Microscopic examinations:}

For microscopic examination, urine specimen was prepared with the following methods.

\section{Centrifugation technique:}

\section{Procedure:}

$10 \mathrm{ml}$ of the collected urine sample was placed into centrifuge tubes. The tube was centrifuged at $2000 \mathrm{rpm}$ for 3 minutes. The supernatant was discarded the deposit was placed on a slide, covered with a cover-slip and examined under a binocular microscope. Eggs were counted, and the result was recorded as eggs count per $10 \mathrm{ml}$ of urine.

\section{Syringe filtration technique:}

\section{Procedure:}

The Isopore ${ }^{\mathrm{TM}}$ Membrane Filter, a product of Merck Millpore Company®, Ireland, is composed of polycarbonate film, which has a smooth, glass-like surface for clearer sample observation.

A polycarbonate filter was carefully placed on the filter holder, using a blunt-ended forceps. A $10 \mathrm{ml}$ syringe was inserted into the upper opening of the filter holder and the plunger was removed. The syringe was filled to the $10 \mathrm{ml}$ mark with the well-mixed urine sample. The plunger was replaced again and the whole setting was held over a $40 \mathrm{ml}$ beaker to let the urine pass into it through the polycarbonate filter. The filter holder was removed and unscrewed. The filter was carefully removed using forceps and transferred face upward onto a slide. A drop of physiological saline was added, and covered with a cover glass. The preparation was examined microscopically; using the 10x objective lens for search and the 40x was then used for identification. The number of eggs was recorded as egg counts per $10 \mathrm{ml}$ of urine.

Nin-hydrin - filter paper staining method: Procedure:

Approximately $40 \mathrm{ml}$ urine was passed through a $12.5 \mathrm{~cm}$ Whatman No. 3, (Whatman International, Maidstone, England) filter paper, folded in a cone. This grade of paper was selected because it was coarse, maintains a cone shape when folded, and it retained both schistosome eggs.

\section{Data management and statistical analysis}

The data collected in this study through the different methodologies was tabulated and then converted into an electronic form. The analysis was of a descriptive and parametric nature. Statistical processing was achieved 
quantitatively and qualitatively using Statistical Package for Social Sciences (SPSS) software. The data analysis was referenced to standard values of the different statistical methods. The computation of the probability (P-value) was carried out through the Chi Square test, whereas the sensitivity and specificity were determined via crosstabulation of data according to the relationship.

Sensitivity $=\frac{\text { True positive }}{\text { True positive }+ \text { false positive }} \times 100 \%$

Specifity $=\frac{\text { True negative }}{\text { True negative }+ \text { false negative }} \times 100 \%$

\section{Results}

The results revealed that the overall prevalence rates of Schistosomahaematobium in Alzaidab, River Nile State were 16.1\%, $24.7 \%$ and $24.7 \%$ using the centrifugation, syringe filtration millipore and ninhydrin filter paper staining method respectively. As shown in table (1), the differences in prevalence rates were found to be highly significant at $\mathrm{P}<0.001$.

According to gender, males showed higher prevalence rates than females using all the techniques mentioned. The difference in rates for all techniques were statistically significant $(\mathrm{P}<0.05)$. The highest prevalence rate in males $(36.1 \%)$ was reported bysyringe filtration millipore and ninhydrin - filter paper staining method (table 2) while the lowest prevalence rate in female $(3.1 \%)$ was reported by the centrifugation, syringe filtration millipore and ninhydrin - filter paper staining method techniques (table 2). According to age groups, the highest prevalence rate was reported among the group of children over 13 years of age, using all the techniques. It was nil $(0 \%)$ among the group of children up to 7 years of age (table 3 ). The differences in rates were statistically significant for the centrifugation, syringe filtration millipore and ninhydrin - filter paper staining method techniques.

The highest prevalence rate $(64.3 \%)$ among the above mentioned group (over 13 year's of age) is shown by the syringe filtration millipore and ninhydrin - filter paper staining method techniques (table 3) and the lowest prevalence rate $(12.8 \%)$ was reported by the centrifugation technique (table 3 ). The result demonstrated that all the positive cases were observed in those who had water contact activities (table 4). Not a single positive case was reported among those who had no contact with water, hence the statistical difference was found to be highly significant at $\mathrm{P}$-values $=0.018,0.002$ and 0.002 for centrifugation, syringe filtration millipore and ninhydrin - filter paper staining method techniques, respectively (table4). The highest prevalence rate among those who had contact with water $(32.9 \%)$ was shown with the syringe filtration millipore and ninhydrin - 
filter paper staining method (table 4) while the lowest prevalence rate $(21.4 \%)$ was reported with the centrifugation technique (table 4). Assuming the centrifugation technique as the gold standard technique, the urine samples were firstly examined by the centrifugation technique. Of the total 93 samples examined, 15 samples were found to be positive for Schistosomahaematobium. The positive cases were examined by the syringe filtration millipore technique showing also 15 positive cases. The 78 urine samples found negative by the centrifugation technique were also subjected to examination by the syringe filtration millipore. Eight samples proved positive, while 70 were negative, constituting a $100 \%$ sensitivity rate of syringe filtration millipore technique and a specificity of rate $90 \%$. Yet, the sensitivity and specificity of the centrifugation technique were $65 \%$ and $100 \%$ respectively when considering the syringe filtration millipore technique the gold standard technique (table 5). Assuming the centrifugation technique as the gold standard technique, the urine samples were firstly examined by the centrifugation technique. Of the total 93 samples examined, 15 samples were found to be positive for Schistosomahaematobium. The positive cases were examined by the ninhydrin - filter paper staining method showing also 15 positive cases. The rest 78 urine samples found negative by the centrifugation technique were also subjected to examination by the ninhydrin - filter paper staining method. Eight samples proved positive, while 70 were negative, constituting a $100 \%$ sensitivity rate of ninhydrin - filter paper staining method and a specificity of $90 \%$. Yet, the sensitivity and specificity rates of the centrifugation technique were $65 \%$ and $100 \%$ respectively when considering the ninhydrin - filter paper staining method as the gold standard technique(table6).

Table 1: Overall prevalence rate of Schistosomahaematobium in Alzaidab, River NileState, Sudan using different techniques.

\begin{tabular}{|l|c|c|c|}
\hline \multicolumn{1}{|c|}{ Technique } & Number examined & Number positive & Prevalence \% \\
\hline Centrifugation & 93 & 15 & 16.1 \\
\hline Syringe filtration millpore & 93 & 23 & 24.7 \\
\hline $\begin{array}{l}\text { Ninhydrin - filter paper } \\
\text { staining method }\end{array}$ & 93 & 23 & 24.7 \\
\hline \multicolumn{2}{|c|}{$P<0.001$} & \\
\hline
\end{tabular}


Table 2: Prevalence rate of Schistosomahaematobium in Alzaidab, River Nile State, Sudan according to gender using centrifugation, Syringe filtration millpore and Ninhydrin - filter paper staining method techniques.

\begin{tabular}{|l|l|c|c|c|c|}
\hline Technique & Gender & $\begin{array}{l}\text { Number } \\
\text { Examined }\end{array}$ & $\begin{array}{l}\text { Number } \\
\text { positive }\end{array}$ & Prevalence \% & Pvalue \\
\hline \multirow{2}{*}{ Centrifugation } & Male & 61 & 14 & 22.9 & $<0.001$ \\
\cline { 2 - 6 } & Female & 32 & 1 & 3.1 & $<0.001$ \\
\hline \multirow{2}{*}{$\begin{array}{l}\text { Syringe filtration } \\
\text { millpore }\end{array}$} & Male & 61 & 1 & 3.1 & $<0.1$ \\
\cline { 2 - 6 } & Female & 32 & 22 & 36.1 & \\
\hline $\begin{array}{l}\text { Ninhydrin - filter } \\
\text { paper staining method }\end{array}$ & Male & 61 & 1 & & \\
\cline { 2 - 6 } & Female & 32 & & & \\
\hline
\end{tabular}

Table 3: Prevalence rate of Schistosomahaematobium in Alzaidab, River Nile State, Sudan according to age group using centrifugation, Syringe filtration millpore and Ninhydrin - filter paper staining methodCentrifugation techniques.

\begin{tabular}{|c|c|c|c|c|c|}
\hline Technique & Age Group & $\begin{array}{l}\text { Number } \\
\text { Examined }\end{array}$ & $\begin{array}{l}\text { Number } \\
\text { positive }\end{array}$ & Prevalence \% & $P$ value \\
\hline \multirow{3}{*}{ Centrifugation } & Up to 7 years & 1 & 0 & 0 & \multirow{3}{*}{$<0.001$} \\
\hline & $8-13$ years & 78 & 10 & 12.8 & \\
\hline & $\begin{array}{l}\text { More than } 13 \\
\text { years }\end{array}$ & 14 & 5 & 35.7 & \\
\hline \multirow{3}{*}{$\begin{array}{l}\text { Syringe filtration } \\
\text { millpore }\end{array}$} & Up to 7 years & 1 & 0 & 0 & \multirow{3}{*}{$<0.001$} \\
\hline & $8-13$ years & 78 & 14 & 17.9 & \\
\hline & $\begin{array}{l}\text { More than } 13 \\
\text { years }\end{array}$ & 14 & 9 & 64.3 & \\
\hline \multirow{3}{*}{$\begin{array}{l}\text { Ninhydrin - filter } \\
\text { paper staining } \\
\text { method }\end{array}$} & Up to 7 years & 1 & 0 & 0 & \multirow{3}{*}{$<0.001$} \\
\hline & $8-13$ years & 78 & 14 & 17.9 & \\
\hline & $\begin{array}{l}\text { More than } 13 \\
\text { years }\end{array}$ & 14 & 9 & 64.3 & \\
\hline
\end{tabular}

Table 4: Prevalence rate of Schistosomahaematobium in Alzaidab, River Nile State, Sudan according to contact with water using centrifugation, Syringe filtration millpore and Ninhydrin - filter paper staining methodCentrifugation techniques.

\begin{tabular}{|l|l|c|c|c|c|}
\hline Technique & $\begin{array}{l}\text { Contact } \\
\text { with water }\end{array}$ & $\begin{array}{l}\text { Number } \\
\text { Examined }\end{array}$ & $\begin{array}{l}\text { Number } \\
\text { positive }\end{array}$ & Prevalence \% & Pvalue \\
\hline \multirow{2}{*}{ Centrifugation } & Yes & 70 & 15 & 21.4 & $<0.001$ \\
\cline { 2 - 6 } & No & 23 & 0 & 0 & $<0.001$ \\
\hline \multirow{2}{*}{ Syringe filtration millpore } & Yes & 70 & 23 & 0 & $<0.001$ \\
\cline { 2 - 6 } & No & 23 & 23 & 0 \\
\hline Ninhydrin - filter paper & Yes & 70 & 0 & 0 \\
\cline { 2 - 6 } & No & 23 & & 0 \\
\hline
\end{tabular}




\begin{tabular}{|c|c|c|c|c|c|}
\hline \multicolumn{2}{|c|}{ 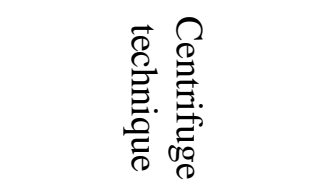 } & \multicolumn{2}{|c|}{ 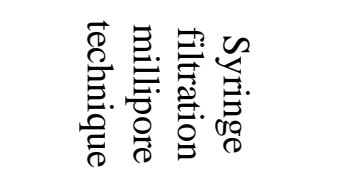 } & \multirow{2}{*}{ 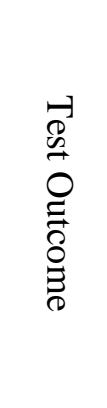 } & \multirow{2}{*}{$\begin{array}{l}\varrho \\
\stackrel{0}{0}:\end{array}$} \\
\hline \multirow[t]{6}{*}{ 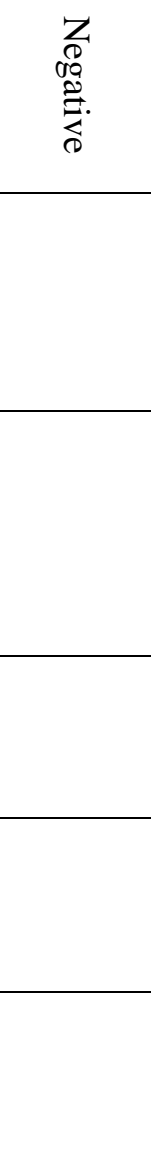 } & 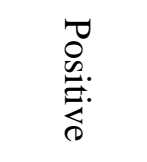 & 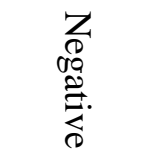 & $\begin{array}{l}0 \\
0 \\
0: \\
0 \\
0\end{array}$ & & \\
\hline & & 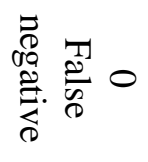 & 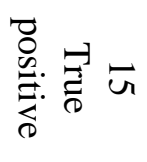 & $\begin{array}{l}\text { D } \\
0 \\
0 \\
0 \\
0\end{array}$ & \multirow{2}{*}{ 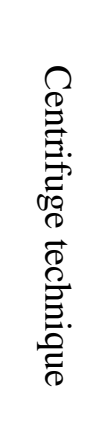 } \\
\hline & & 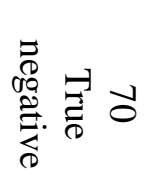 & 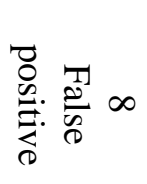 & 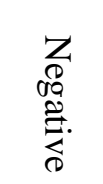 & \\
\hline & & তे & 心 & $\begin{array}{l}\overrightarrow{0} \\
\stackrel{0}{\triangleq}\end{array}$ & \\
\hline & & & $\begin{array}{l}\overrightarrow{8} \\
8\end{array}$ & 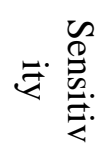 & \\
\hline & & & $\begin{array}{l}0 \\
8 \\
0\end{array}$ & 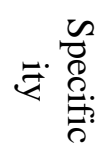 & \\
\hline 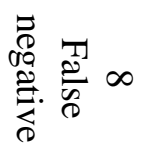 & 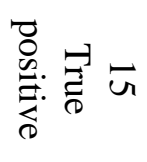 & & & $\begin{array}{l}\text { D } \\
0 \\
0 \\
0 \\
0\end{array}$ & \multirow{2}{*}{ 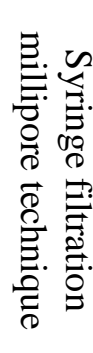 } \\
\hline 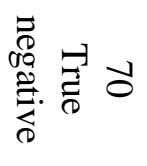 & 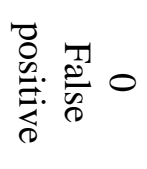 & & & 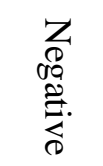 & \\
\hline \multirow[t]{3}{*}{ ఎ } & $\vec{r}$ & & & $\stackrel{\overrightarrow{0}}{\stackrel{0}{ٍ}}$ & \\
\hline & $\begin{array}{l}\text { जो } \\
\text { di }\end{array}$ & & & 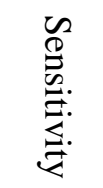 & \\
\hline & $\begin{array}{l}\overrightarrow{8} \\
8 \\
\end{array}$ & & & 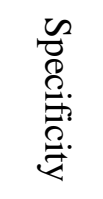 & \\
\hline
\end{tabular}

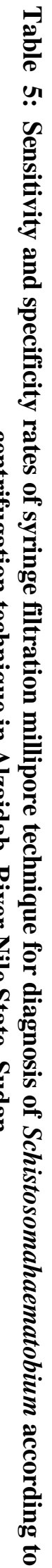




\begin{tabular}{|c|c|c|c|c|c|}
\hline \multicolumn{2}{|c|}{ 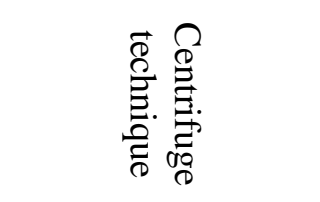 } & \multicolumn{2}{|c|}{ 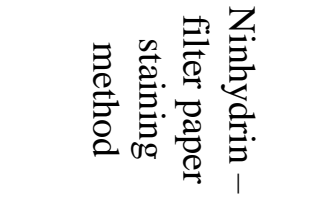 } & \multirow{2}{*}{ 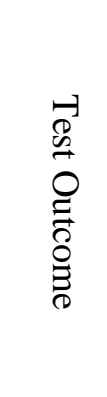 } & \multirow{2}{*}{$\begin{array}{l}\delta \\
\stackrel{0}{0}: \\
0\end{array}$} \\
\hline \multirow[t]{6}{*}{ 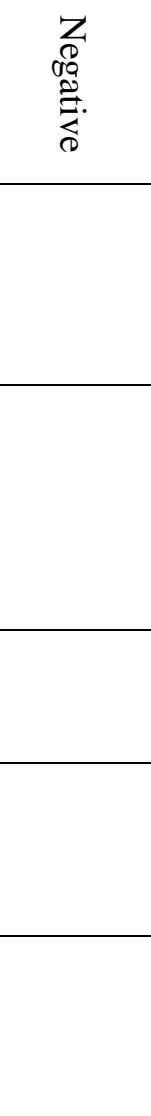 } & 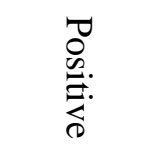 & 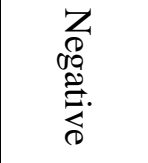 & $\begin{array}{l}0 \\
0 \\
0 \\
0 \\
0 \\
0\end{array}$ & & \\
\hline & & 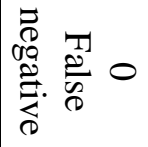 & 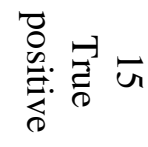 & $\begin{array}{l}\overrightarrow{0} \\
0 \\
0 \\
0 \\
0\end{array}$ & \multirow{2}{*}{ 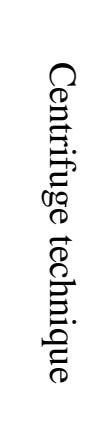 } \\
\hline & & 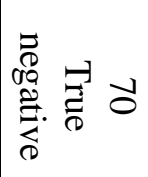 & 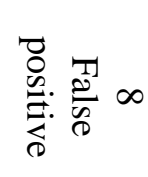 & 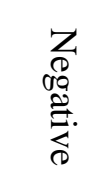 & \\
\hline & & ত & $\tilde{\omega}$ & $\stackrel{\overrightarrow{0}}{\stackrel{0}{\tilde{D}}}$ & \multirow{5}{*}{ 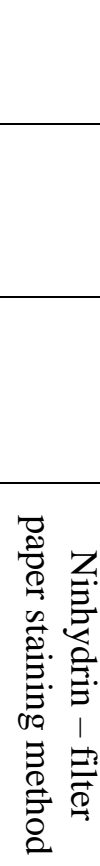 } \\
\hline & & & $\frac{5}{8}$ & 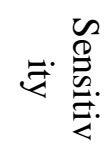 & \\
\hline & & & $\begin{array}{l}8 \\
\& \\
0\end{array}$ & 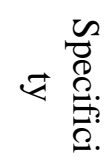 & \\
\hline 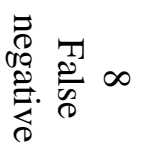 & 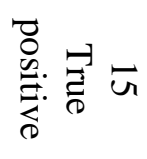 & & & $\begin{array}{l}0 \\
0 \\
0 \\
0 \\
0 \\
0\end{array}$ & \\
\hline 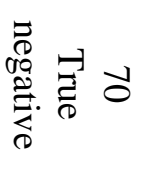 & 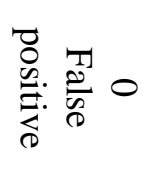 & & & 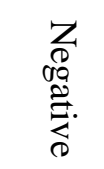 & \\
\hline \multirow[t]{3}{*}{ ఎ } & $\vec{u}$ & & & $\stackrel{\overrightarrow{0}}{\stackrel{0}{\Xi}}$ & \\
\hline & जो & & & 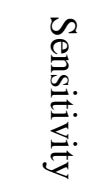 & \\
\hline & $\frac{8}{8}$ & & & 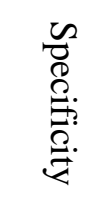 & \\
\hline
\end{tabular}

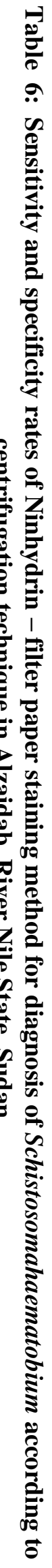




\section{Discussion}

This study was an attempt to set a comparative analysis of some techniques adopted for the diagnosis of urinary schistosomiasis. These techniques included the centrifugation, syringe filtration millipore and ninhydrin - filter paper staining methods. The study subjects were categorized according to age, gender groups and groups who had or had not contact with water. The centrifugation method gave a higher prevalence rate in males $(22,9 \%)$ compared to that in females $(3.1 \%)$. This result is similar to the higher prevalence rate of $45.9 \%$ amongst males and 34\% among females in Sinnar crescent(Abosalif, 2004).A clear difference between the Schistosomahaematobium infections situation in males and females, $27 \%$ and $11 \%$ respectively,wasdemonstrated(Elbasheir, 2010). A similar result was reported showing comparable Schistosomahaematobium infection patterns among girls and boys(Eldirdieri, 1994).

It was reporte that the syringe filtration was highly more sensitive than centrifugation technique in qualitative diagnosis of Schistosomahaematobium infection(Afifi, 2009). It is worthmentioning that the results presented in this work by the syringe filtration millipore and the ninhydrin - filter paper staining method were entirely identical for all the groups tested. Similar results were reported by(Mottetaj., 1982)when comparing ninhydrin stained paper filter with syringe filtration of urine to detect Schistosomahaematobium eggs in the urine under field conditions. In this study, the prevalence of infection with Schistosomahaematobium increases remarkably from 13 years of age and above.El-Khoby found that the infection by Schistosomahaematobium peaked at $15.7 \%$ amongst children of $10-14$ years of age and decreased to $3.5-5.5 \%$ in all groups more than 25 years (El-Khobyet al., 2000). Similar results were shown byAfifi, who mentioned that the prevalence of infection with Schistosomahaematobium increases with age group 10 to 20 years(Afifi, 2009). This general pattern in different endemic areas is closer to the international level(Marcal-Junior et al., 1993).Likewise, many national reports related the different age classes to the infection parameters of schistosomiasis(Ahmed, 2002 and Abd-Ellah, 2008).The age-sex related patterns of prevalence of Schistosomahaematobium infection observed in the present study are in agreement with the patterns found in many others endemic settings. Reports from Sudan, GhanaandLiberiaagreed that the decreasing prevalence of infection in older age group might probably be due to the less frequencywith water contact in old age and the same applies for sex(Elbasheir, 2010; Eldirdieri, 1994; Elias, 1992; Scott et al., 1982 andKazuraet al., 1985). Higher 
prevalence rates were detected among waterrelated jobs than among other occupants. In Gunaid sugar cane scheme, as previouslyreported,the water contact activities were mainly influenced by many factors like culture, temperature and accessibility to water supply(Ahmed, 1998 \& 2002). Females are usually involved in domestic water-contact activities, like washing clothes, utensils as well as water fetching. Male adults are normally exposed to water through activities as fishing and farming irrigation while contact for religious reasons may be practiced in muslim communities, where ablution is carried out before praying. In children, the most important recreational aspects are found in water-contact activities, where a considerable part of the body is exposed to water for an ample time. Chances of being infected depend upon the duration of water-contact, the degree of body exposure and density of cercariae in infested waterbodies. So, bathing and swimming constitute a higher risk than water collection. Also, the higher the frequency and the longer the duration of water-contact, the greater the risk of acquiring the disease(Davis, 1993).Activities involving water contact; particularly bathing and swimming have been shown to play an important role in schistosomiasis transmission(Elbasheir, 2010;Hilali, 1992 and Gamal,1992).In this study, an association was observed between the highest prevalence rate among children and the water contact using all techniques.

\section{Conclusions and Recommendations}

The comparative study of the three diagnostic techniques revealed several attributes that distinguish between their diagnostic capacities. The following conclusions and recommendations can be withdrawn:

1- The centrifugation technique is recommended in severe or medium cases of Schistosomahaematobium infections. However, in cases of chronic and light infections, where few eggs are shed in urine, the technique might fail to detect the infection.

2- A better technique for field epidemiological survey can be the syringe millipore filtration method, since the filtration enables the retention of all eggs without loss, yet in cases of light or chronic infections the detection of eggs might be missed.

3- The Ninhydrin filter paper staining method is reliable, but can only be carried out inside the laboratory and does not fit for field work. 


\section{References:}

Abd-Ellah, I. (2008). Observation on transmission pressure of schistosomiasis in ElGazira agricultural scheme. Sudan. M.Sc. Thesis, University of Khartoum. Faculty of Sciences.

Abosalif, K. O. (2004). Evaluation of various techniques used for the diagnosis of schistosomiasis, M.Sc thesis, AlzaiemAlazhary University. Faculty of Medical laboratory Sciences.

Afifi, A. (2009). Epidemiological investigation of schistosomiasis and intestinal parasites in New Halfa agricultural scheme, Sudan. Ph. D. thesis, University of Khartoum, Faculty of Sciences.

Ahmed, A. (1998). Epidemiology of Schistosomamansoni infection in Gunaid Sugar Scheme, Gezira state. Ph.D. thesis, University of Khartoum, Faculty of Sciences.

Ahmed, A. (2002). Micro epidemiology factors influencing transmission pressure of schistosomiasis in Gunaid Scheme, Sudan. J. Nat. Scien. Vol 2 (B).

Davis, A. (1993).Antischistosomal drugs and clinical practice. In: Jordan $\mathrm{P}$ and Webbe G. Sturrock FS. Human schistosomiasis. Wallingford: CAB International. 367- 369.
Elbasheir, M. M. (2010). Assessment of Circulating Cathodic Antigen Urine strip Test and Real-time Polymerase Chain Reaction Techniques in Diagnosis of schistosomiasis in Central Sudan. Ph. D. thesis, AlzaiemAlazhary University. Faculty of Medical laboratory Sciences.

Eldirdieri, S. (1994). Infection, disease and transmission patterns in human schistosomiasis in the White Nile Province, Sudan. M.D. thesis, Faculty of Medicine, University of Khartoum. Sudan.

Elias, E. (1992). Transmission of urinary schistosomiasis on the Rahad Irrigation Scheme, Sudan. Ph.D. thesis, Department of Zoology, Faculty of Sciences, University of Khartoum. Sudan.

El-Khoby, T., Galal, N., Fenwich, A., Barakat, R., El-Hawey, A., Nooman, Z., Habib, M., Abdel- Wahab, F., Gabr, N., Hammam, H., Hussein, M., Mikhail, N., Cline, B. and Strickland, G. T. (2000). The epidemiology of schistosomiasis in Egypt. Schistosomiasis Research Project. The Egyptian Organization for Biological and Vaccine Production, Agouza. Egypt. Am. J. Trop. Med. Hyg. 62: 88-99. 
Eltayeb, M. (1998). Morbidity due to Schistosomamansoni. Ph. D. thesis, University of Khartoum. Faculty of Medicine.

Gamal, H. (1992). The epidemiology of Schistosomamansoni in the GeziraManagil area of Sudan. Impact of the Blue Nile Health Project. Ph.D. thesis, Department of Biological Anthopology, University of Cambridge, England.

Gryseels, B., Polman, K., Clerinx, J. and Kestens, L. (2006). Human schistosomiasis. Lancet, 368: 11061118.

Hammam, H., Zarzour, A., Moftah, F., Abdel-Aty, M., Hany, A., El-Kady, A., Nasr, A., Abd-El-Samie, A., Qayed, M., Mikhail, N., Talaat, T. and Hussein, M. (1933). The epidemiology of schistosomiasis in Egypt. Department of Community Medicine, Faculty of Medicine, Assiut University. Egypt. Am. J. Trop. Med. Hyg. 62: 88-7.

Hilali, A. (1992). Transmission of Schistosomamansoni in the Managil area, Sudan. Ph. D. thesis, Department of Zoology, Faculty of Sciences, University of Khartoum, Sudan.

Kazura, J., Neill, M. and Dennis, E. (1985). Swamp rice farming: Possible effects on endemicity of
Schistosomamansoni and

Schistosomahaematobium in a population in Liberia. The Am. J. Trop. Med. Hyg. 34: 107 - 111.

Marcal-Junior, O., Hotta, L. K., Patucci, R., and Dias, L. (1993). Schistosomiasis in an area of low transmission. II. Risk factors for infection. Am. J. Trop. Med. Hyg. 35 (4): $331-335$.

Mott, K. E., Baltes, R., Bambagha, J. and Baldassini, B. (1982). Field studies of a reusable polyamide filter for detection of Schistosomahaematobium eggs by urine filtration. TropenmedParasitol. 33(4): $227-8$.

Quack, T., Beckmann, S. and Grevelding, C. (2006).Schistosomiasis and the molecular biology of the malefemale interaction of Schistosomamansoni.Ber Munch TierarztlWochenschr 119: 365-372.

Ross, A., Bartley, P., Sleigh, A., Olds, G. and Li, Y. (2002) Schistosomiasis. N. Engl. J. Med. 346: 1212-1220.

Ross, A., Vickers, D., Olds, G., Shah, S. and McManus, D. (2007). Katayama syndrome. Lancet Infect. Dis. 7: 218224.

Scott, D., Senker, K. and England, E. (1982). Epidemiology of Human 
Schistosomahaematobium infection

around Volta Lake, Ghana, 1973-1975.

Bulletin of World Health Organization.

60: 80-100. 